\author{
Iman S. Kareem \\ Electromechanical \\ Engineering Depart., \\ University of Technology \\ Baghdad, Iraq \\ 50071@uotechnology.edu.iq
}

Received on: $15 / 11 / 2018$

Accepted on: 10/01/2019

Published online: 25/12/2019

\section{Instructional Design for Engineering System Based Software Cycle Methodology (IDSCM)}

Abstract- An instructional program has been prepared depending on instructional design concepts to present concepts and information of an engineering system. The design and construction of an instructional program have done by using analysis design implementation and evaluation (ADDIE) instructional model. It is used for simulation the designing of engineering system using modern and intelligent controller technique. The simulation design was dependent on new methodology is named software cycle method. To achieve the aims from the program a questionnaire is prepared to evaluate the program by a number of experts and beneficiary groups. The result of the questionnaire is used as a feedback process. A development is done to achieve the link between two different techniques. Designing instructional program under windows to be used by designer engineers and students may help to learn the design steps for modern technique and intelligent technique.

Keywords- ADDIE, software cycle, intelligent technique, simulation.

How to cite this article: I.S. Kareem, "Instructional Design for Engineering System Based Software Cycle Methodology (IDSCM)," Engineering and Technology Journal, Vol. 37, Part C, No. 4, pp. 418-426, 20119.

\section{Introduction}

The development in engineering systems needs more accurate and sensitive in its implementation. So for this reason, to build any instruction model for engineering project, there must be a sufficient knowledge about the apparatus's as possible. Most of the modern control engineering systems are nonlinear, or complex in their mechanical and electrical design. Simulation with animation is very good training, for managers, supervisors, and engineers. With system of complex physical, the simulation animation is an excellent method in that most entrants are visualizing how their work participates for all system success or troubles $[1,2]$.

The simulation modeling is a depictive modeling of a process or system, and it contains elements that specify the modeling to be configurable, which is, to illustrate a number of somewhat different systems or operation configurations.

There are one or more of the following objectives to build the simulation model: [3]

1. Describe a present system.

2. Explore a virtual system.

3. Design a developed system.

Evaluation comparison and analysis are the key causes for making simulation.

Estimation of system execution and identification of system troubles and their reasons are the key results [4].
This paper, present a work in designing and developing model for engineering system that improving beneficiary groups' cognitive skills.

\section{Instructional Technology and Instructional Design}

Technology of Instruction it is the systematic with their implementation of strategies and techniques obtained from behavioral, cognitive, and constructivist theories to the solution of instructional trebles. Instruction may be used as equivalent for educational technology, with this idea:

Instructional Technology $=$ Instructional Design + Instructional Development

Instruction Technology / Design etc. have the most "industrial" or engineering property than Educational Technology / Pedagogical Designs. Instructional design is a part of knowledge involved with research and theory about instruction strategies and the method for development and implementation those strategies. [5].

There are four different prospects for Instructional design: [6]

1. Instructional Design as a Process.

2. Instructional Design as a Discipline.

3. Instructional Design as a Science.

4. Instructional Design as Reality. 


\section{Instructional Design (I.D.) Methods and Models}

The definition of the instructional design method is how to organize the perfect design process, where as an instructional design modeling illustrates a class of an educational design, i.e. how to learn, how to get people to learn, etc. The modeling is a method, i.e. a general design rule on how to learn/get to learn.

Instructional design model always has a robust concentrate on learning theories than instructional design method. The value of an appointed model is obtained within the context of using. Like any other tool, a model assumes a special aim of its user. A model should be arbitrate by how it arranges the designer's goal, how well it can division a work load, and how effectiveness it shifts focus away from itself toward the target of the design action.[5]

Many presented instructional models indicate that the more active learning outputs or environments are those that are problem centered and cover the student in a cycle of learning which includes four special phases as shown in Figure 1: $[7,8]$.

- Activation of before experience

- Demonstration of skills

- Application of skills

- Integration of these skills into actual world effectively.

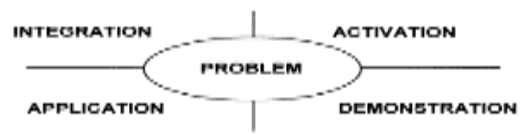

Figure 1: phases of active instruction

\section{ADDIE Model for Instructional system Design}

Analysis, Design, Development, implementation, and Evaluation (ADDIE) is the common purpose modeling .it more benefit for making instructional outputs, but also useable for programming design. These stages sometimes overlap and can be related each to other; yet, they spread a dynamic, adaptable guideline for development active and effective instruction.

The ADDIE Model is a repeated instructional design process, where the results of the formative evaluation of each stage may set the instructional designer back to any previous stage. The output of one stage is an input of the next stage. Figure 2 illustrates ADDIE model structure [9].

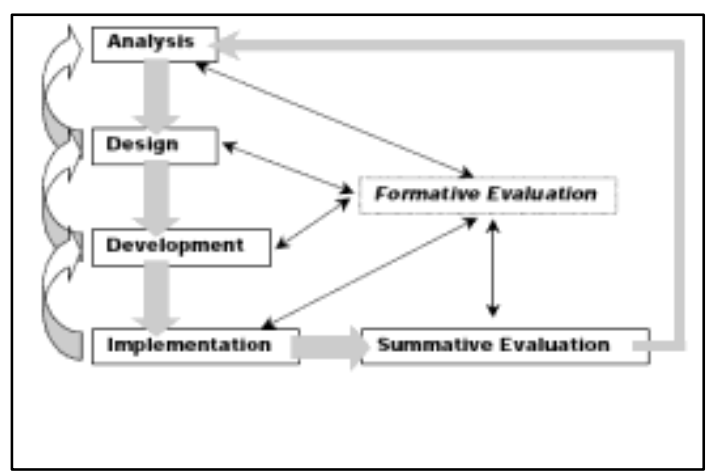

Figure 2: ADDIE model structure [9]

\section{Software Cycle for Simulation Model}

The aim of the design is provided a credible technique for an iterative design of successful and applicable interacting systems. It is therefore important that is going beyond the practice of identification models and principles and testing the process of interacting system design. Programming supporting for simulation means a designer can rapidly construct graphical and textual interacting goals and connect some behavior to those aims that simulate a functionality of the system. [10]

The simulation is constructing; one of the fundamental of software engineering is the software cycle, which depicts the actions which take place from the first concept formation for the software system up until its final stage out and replacement. The block diagram in figure (3) depicts the software cycle. Where, the requirement specification, the designer and user is capturing the depicting of what the final system will be predictable to prepare.

The detailed design is an improvement of the component depiction as long as by a structural design. The detailed design for components of the system should be in such a form which it can be implemented it in some executable programming language. Most of the engineering works in formal methods drives under the hypothesis that, in theory, the transformation from the detailed design to the operation is from one mathematical modeling to another and so should be able to be completely automated. Once enough component has been done and separately examined, it must be integrated as illustrate in the structural design. Moreover a testing is done for ensuring correctly behavior and agreeable use any shared resources. It can at this time to perform some agreeable testing with the users for ensuring that the system meets their requirements. Maintenance includes the correction of errors is detected for the proposed system, which after appearance and the modification of the system services to fulfill needing which were not appearance during 
previous developing. Therefore, maintenance supply's feedback for all the other actions in the software cycle, as shown in Figure 3, [11,12].

\section{Instructional design procedure}

ADDIE model has been used in designing the instructional program with instructional development by software cycle methodology. This methodology applied on an engineering system. Figure 4 shows the flowchart of the instructional procedures.

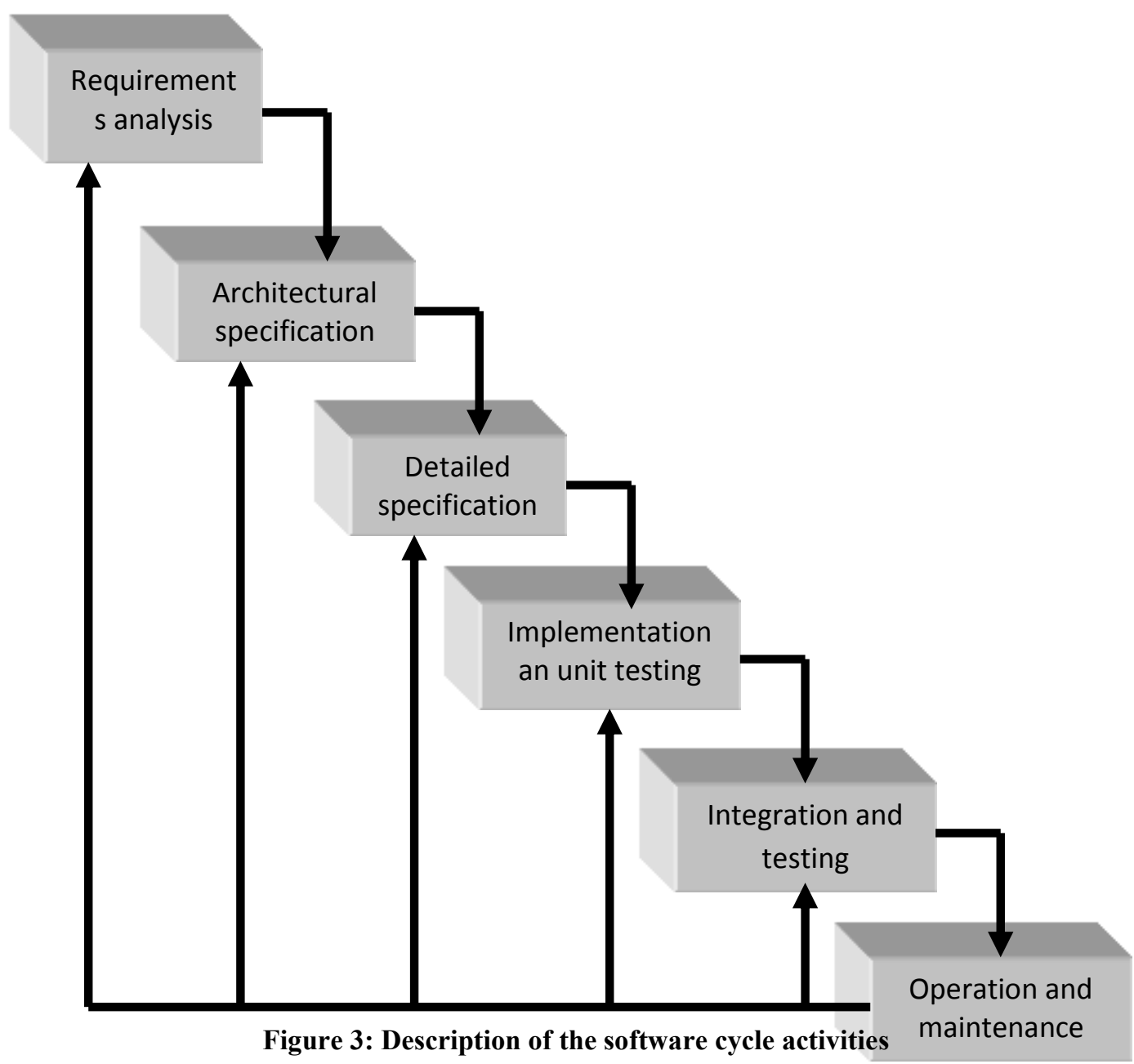




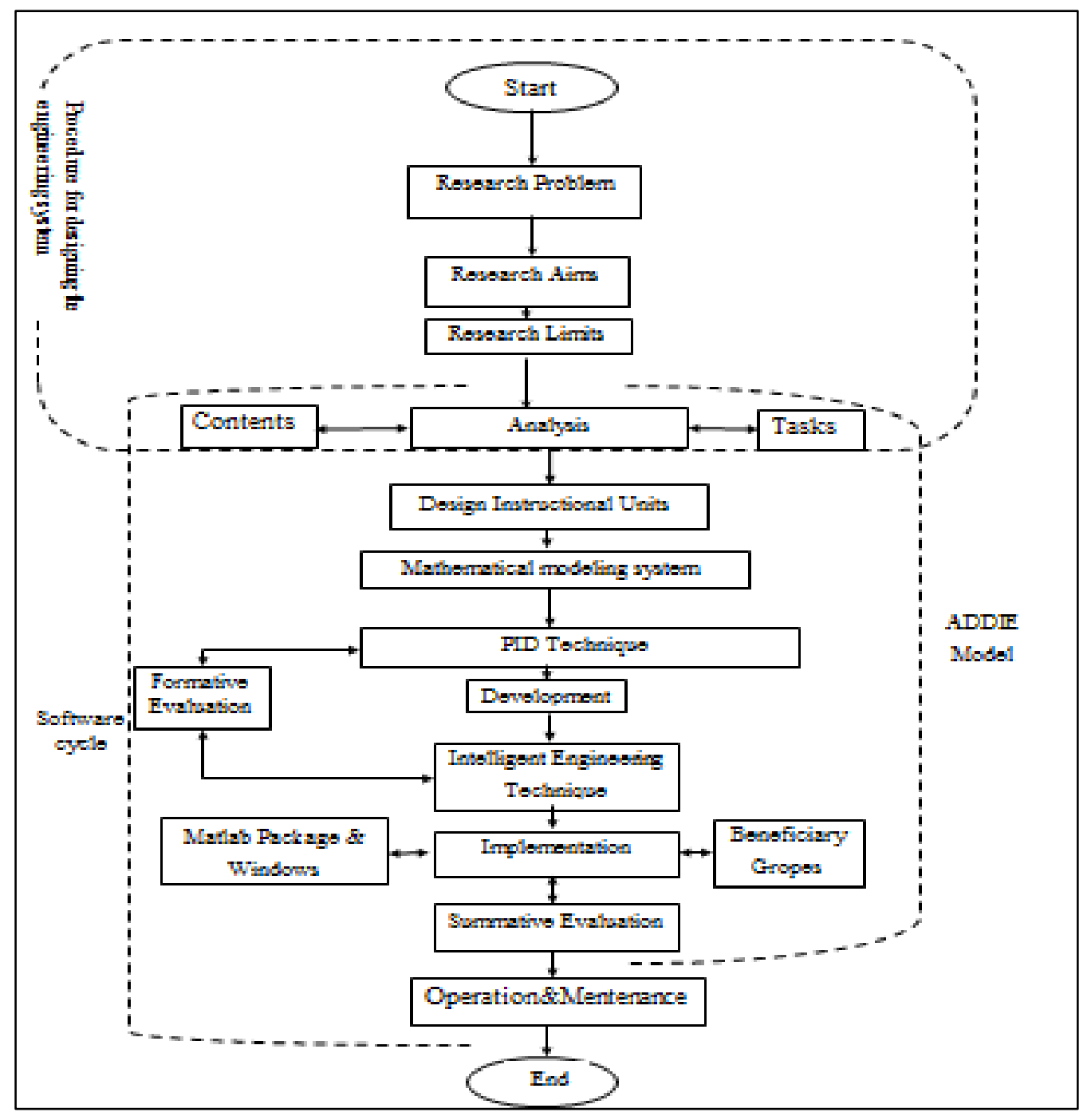

Figure 4: Flowchart for procedure of instructional Design based software cycle

\section{Research problem}

The problem of the proposed research can be summarized as a scientific question" How to think about design of a digital temperature control system? What are the strategies for implementation a controller using the Popular PIC Microcontroller PIC16F877A? “.

It must be specifying the difficulties which are facing the instructional designer as follows:

1-The difficulty is understanding the intelligent controller to improve the efficiency and reliability of the system. This process needs an advanced soft computing technique.

2-The students are facing difficulties to understand the procedure of the intelligent technique design .In another word there are hidden steps in this process like how to transform the parameters of the system which are used in modern technique to that will use in the intelligent technique.
3- The engineers face difficulties to design the model .The stage may contain special research requirements such as needs analyzing of job and task. A final step of this stage usually contains an instructional aims, and a set of tasks which will instructed. This final step is the starting step for the design stage.

\section{Research Aims}

The main aims of this design can be summarized as follows:

1) To increase the experience of the engineers and student in the proposed engineering system.

2) To create the instructional knowledge about investigation the replacement process between the two different techniques.

\section{Research limits}

This research is limited to use 1. Matlab Package as programing tool 2. ADDIEA model 
3. A suitable choice of media and materials to present the contents of instructional program with homogeneous colors and voice attracts the learner's attention and encourages them to continue with program using control buttons for moving forward and backward through the program. The instructor needs to know the level, skills and knowledge of learners before and after the instructional course or unit.

4) The beneficiary groups (student in engineering college\& engineering working in electric and control system)

\section{Analysis}

The following tasks are achieved by this phase:-

1. Collecting the necessary information which is included

- References related to the case study.

- Procedure for the Theoretical design

- Procedure for the practical design of an intelligent technique

- Data required by the engineering program are provided, which can be classified into two types (analog and digital data).

- Saving all the theoretical results with evaluation.

2. Specifying the instructional method

ADDIE instructional model is employed to design and implement the instructional program.

3. Specifying the programming languages

MATLAB software program is applied to simulate an engineering system. Power Point computer program is applied to show the instructional design program because of its fascinating abilities and techniques.

\section{Design}

The design stage includes the using of the outputs from the analysis stage to plan a strategy to develop the instructional process. In this stage, you must outline how to achieve the aims of instructional, where found during the analysis stage and developed the instructional basis. Some of the components of the design stage may contain displaying a goal population depiction, directly a learning analysis, displaying aims and testing items, selecting a transmission system, and sequencing the instructional. A final step of the design stage will be the starting step for a development stage.

\section{Development}

The development stage constructs from the two stages, the analysis and design stages. The intent of this stage is to create the lesson plans and lesson materials through this stage we will need an improvement the instruction by:

1. Using all the modern media in the instruction.

2. Any supporting documentation.

3. Instructional design experts.

This may contain hardware components and software (computer based on instruction).

\section{Implementation}

An Implementation stage indicates to the real transmission of the instruction, whether it is classroom-based, lab-based, or computer-based. The purpose of this stage is the active and effective transmission of instruction.

Implementation stage enhance to:

1. The understanding of students for material.

2. Supporting the mastery for the students of aims.

3. Guarantee the students' transfer of knowledge from the instructional setting to the system.

\section{Evaluation}

Evaluation stage finds the activity and effective of the instruction. Evaluation should happen during the complete instructional design process during the stages, between stages, and after implementation. The proposed design is (IDSCM) used for engineering system is shown in the Figure 5. It is divided into separate and smaller elements. The final output is released as a series of outputs, each subsequent consisting one or more element.

In the present research, each unit in the program is evaluated by supervisors and users. An evaluation questionnaire list of experts was organized. It consists (10) items as shown in Table 1 in order to get opinion about the effectiveness the instructional program. Another list of questionnaire of users was organized, which is shown in Table 2 to get opinion about the program and the benefits they have through using this program.

\section{Statistical Method}

For the present research purposes, used the weighted arithmetic mean for analyzing the results. The arithmetic mean is obtained after analyzing the items of the questionnaire and determining the repetitions of the answers that are given by the beneficiary groups. The questionnaire was composed in accordance with Likert scale in which the answer is being distributed on the items with five weights, graduated in compliance with their levels, and given (5) degrees for the highest weights and (1) degree to the lowest weight. Table (3)shows the 
weight of the answer, and the calculation of the values for the weighted arithmetic mean are used the equation (1): [12]

$$
\bar{X}=\frac{n_{1} x_{5}+n_{2} x_{4}+n_{3} x_{3}+n_{4} x_{2}+n_{5} x_{1}}{n}
$$

$\bar{X}=$ arithmetic mean.

$\mathrm{n}=$ number of those answered the questionnaire items. $\mathrm{n} 1 \ldots \mathrm{n} 5=$ repetition of the answer.

$\mathrm{X} 1 \ldots \mathrm{x} 5=$ Weight of the item.

where:

Designing components figure.(3)

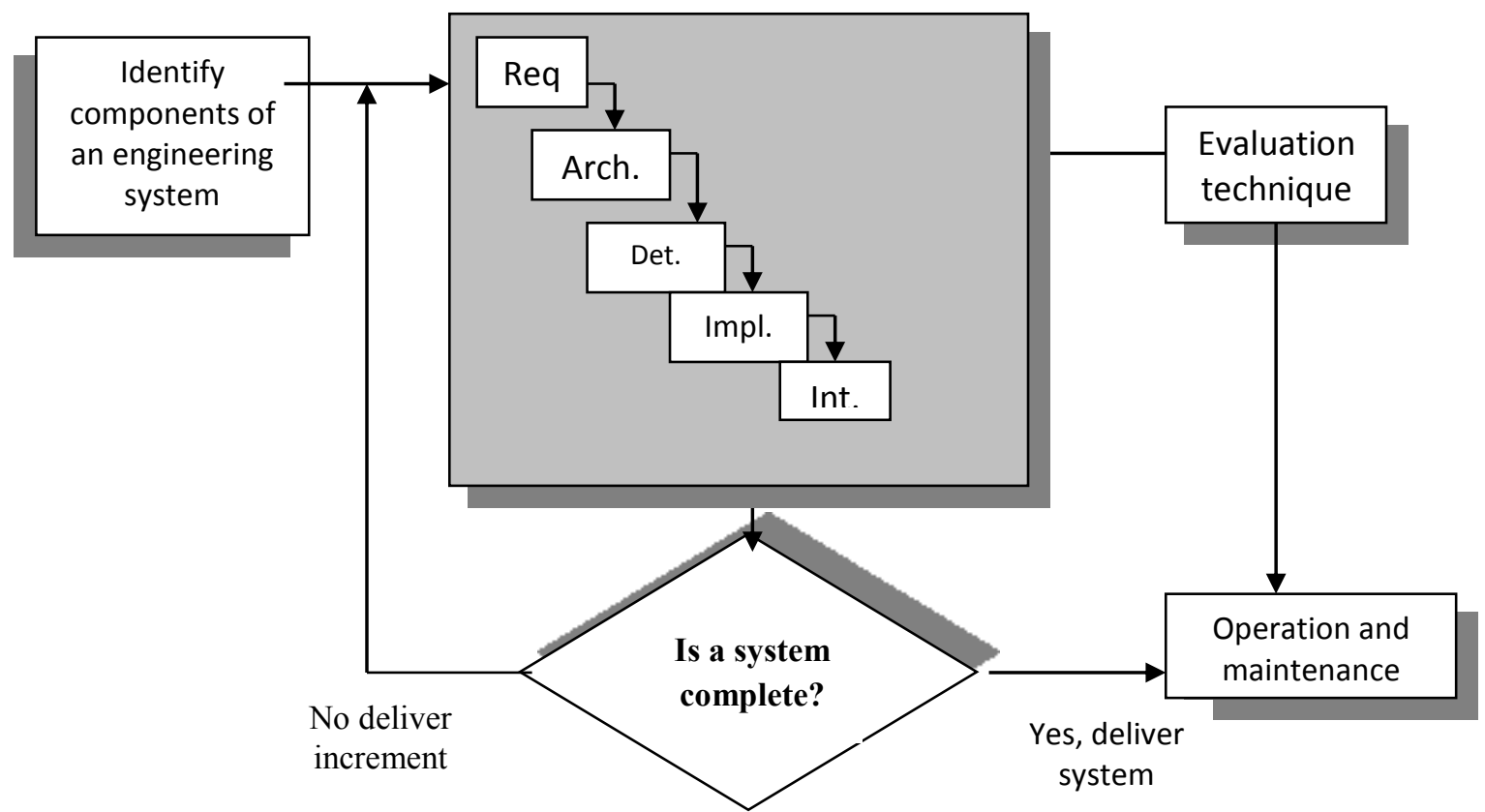

Figure 5: Overall design for the final instructional development software Cycle

Table 1: Expert's questionnaire form about the Instructional Program

University of Technology

\section{Electromechanical Engineering Department}

\section{Dear Sir}

Please, accordance to your scientific and instructional experience answer these questionnaire items which concern in (instructional program for design temperature control system), by selecting one choice out of five representing the effectiveness of the instructional program. Please tick $(\sqrt{ })$ in the space that represents your choice.

\section{The researcher}

\begin{tabular}{|c|c|c|c|c|c|c|c|}
\hline No. & Items & $\begin{array}{l}\text { Degree } \\
\text { Excellent }\end{array}$ & $\begin{array}{l}\text { Very } \\
\text { Good }\end{array}$ & Good & Poor & $\begin{array}{l}\text { Very } \\
\text { poor }\end{array}$ & $\begin{array}{l}\text { ARITHMETIC } \\
\text { MEAN }\end{array}$ \\
\hline 1 & $\begin{array}{l}\text { Introduction to program participates in } \\
\text { identifying scientific standard }\end{array}$ & 6 & 4 & & & & 4.6 \\
\hline 2 & Goals of instructional program are clear & 9 & 1 & & & & 4.9 \\
\hline 3 & Simulation language is clear \&suitable & 8 & & & & & 4.8 \\
\hline 4 & Instructional program insure self-learning & 7 & 3 & & & & 4.7 \\
\hline 5 & ADDIE model is effective & 9 & 1 & & & & 4.9 \\
\hline 6 & $\begin{array}{l}\text { The sequence used software cycle methodology } \\
\text { is effective and simple }\end{array}$ & 10 & & & & & 5 \\
\hline 7 & $\begin{array}{l}\text { Flowchart and picture enhance learners } \\
\text { motivation }\end{array}$ & 10 & & & & & 5 \\
\hline 8 & Colors used are suitable for display & 9 & 1 & & & & 4.9 \\
\hline 9 & $\begin{array}{l}\text { The suitability of amount of data in the } \\
\text { instructional unit is adequate }\end{array}$ & 9 & 1 & & & & 4.9 \\
\hline 10 & Test questions in the program are clear & 9 & 1 & & & & 4.9 \\
\hline
\end{tabular}


University of Technology

Table 2: Questionnaire of Learner's about the Instructional Program

\section{Electromechanical Engineering Department}

Dear Student

You have in your hands items of questions deal with using the instructional program (instructional program for design temperature control system). We would like to know your opinion by ticking $(\sqrt{ })$ in the suitable place representing your choice. Your answer will help supporting and modifying the instructional program.

The researcher

\begin{tabular}{|c|c|c|c|c|c|c|c|}
\hline \multirow[t]{2}{*}{ No. } & \multirow[t]{2}{*}{ ttems } & \multicolumn{6}{|l|}{ Degree } \\
\hline & & Excellent & $\begin{array}{l}\text { Very } \\
\text { Good }\end{array}$ & Good & Poor & $\begin{array}{l}\text { Very } \\
\text { Poor }\end{array}$ & $\begin{array}{l}\text { Arithmetic } \\
\text { mean }\end{array}$ \\
\hline 1 & $\begin{array}{l}\text { Goals and objectives of instructional } \\
\text { program are clear }\end{array}$ & 10 & & & & & 5 \\
\hline 2 & $\begin{array}{l}\text { Instructional program is easy to use by } \\
\text { learners }\end{array}$ & 9 & 1 & & & & 4.9 \\
\hline 3 & Scientific contents are clear and simple & 6 & 4 & & & & 4.6 \\
\hline 4 & $\begin{array}{l}\text { The displayed information density on } \\
\text { computer screen is suitable }\end{array}$ & 8 & 2 & & & & 4.8 \\
\hline 5 & $\begin{array}{l}\text { The software cycle Simulation model } \\
\text { increases learning desire }\end{array}$ & 10 & & & & & 5 \\
\hline 6 & $\begin{array}{l}\text { Pictures \&graphics rouse Learner's } \\
\text { motivation }\end{array}$ & 10 & & & & & 5 \\
\hline 7 & $\begin{array}{l}\text { The questions in the instructional program } \\
\text { are clear }\end{array}$ & 10 & & & & & 5 \\
\hline 8 & Colors used are suitable for display & 9 & 1 & & & & 4.9 \\
\hline 9 & The program reduces the time for learning & 9 & 1 & & & & 4.9 \\
\hline 10 & $\begin{array}{l}\text { ADDIE instructional model adoption is } \\
\text { effective }\end{array}$ & 10 & & & & & 5 \\
\hline
\end{tabular}

\begin{tabular}{ccc}
\hline \hline No & The answer & The weight $(\mathbf{x})$ \\
\hline 1. & excellent & 5 \\
2. & Very good & 4 \\
3. & Good & 3 \\
4. & Poor & 2 \\
5. & Very poor & 1 \\
\hline
\end{tabular}

Table 3: Weight of the answer in the questions
5. Based on questioner results, the instructional program helps to create an effective learning environment to achieve the desired objectives. Another point reducing the potential and time required to learn the proposed system.

\section{Widows from instructional Design program}

\section{Conclusions}

The following points refer to the main conclusions drawn from the current research:

1.An engineering model with huge component the operation cannot be performed directly so the hypothetical model proposed to learn the user an instructional program is designed with software methodology shows all the designing components 2. The proposed Instructional design goals for a learner-centered rather than the conventional teacher-centered approach to instruction, so that active learning will take place.

3. Designing instructional program under windows using by engineering and students helpful to learning process for modern or intelligent techniques which is used in the engineering systems

4. The proposed design is (IDSCM) an excellent model to show the theoretical and practical procedure for any engineering system 


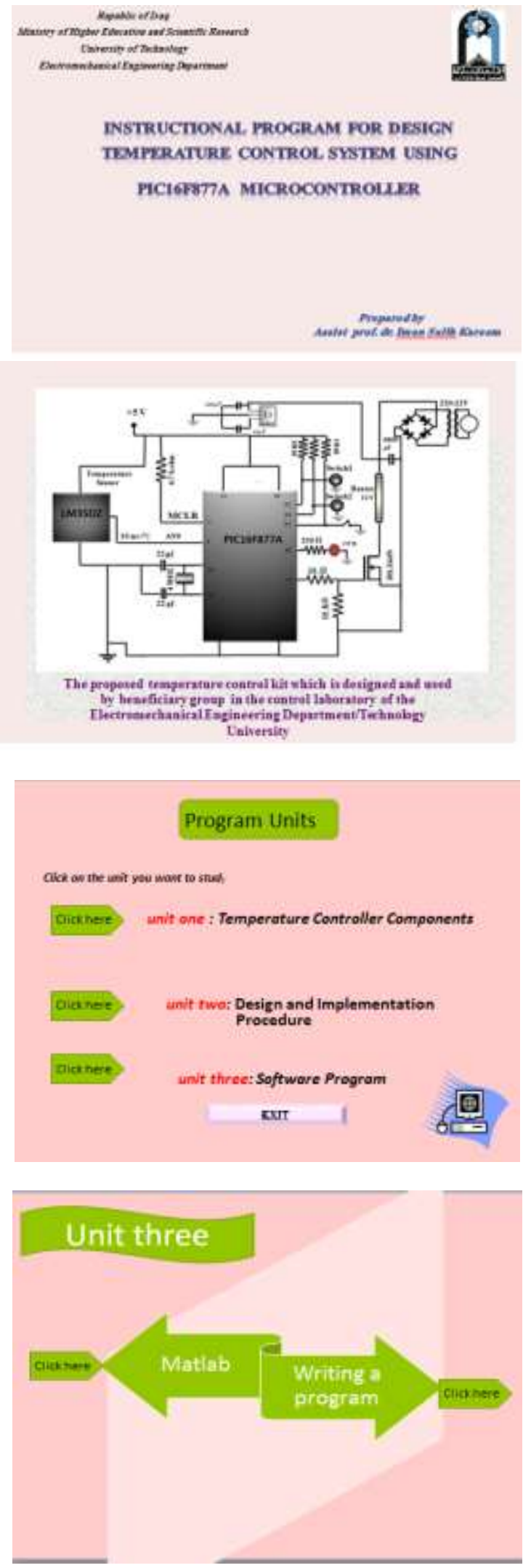

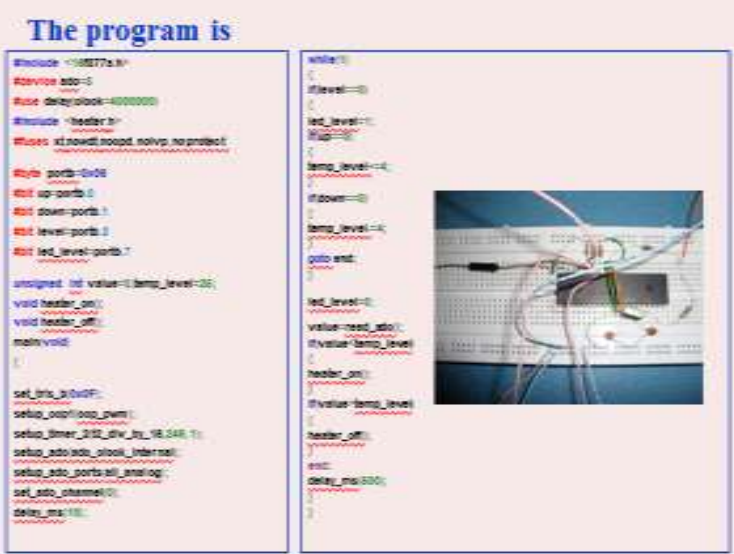

Temperature control unit

The block diagram of the digital tempernture control system shown below

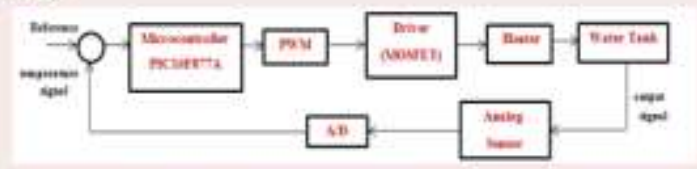

Thu processis used to teoch the following important concepts to the stadent:

- Modeling and ifruelifeathen of a real phyaical process.

- Ving mierocontroliers ia process ausumarion.

- Iesting and experimentiag the temperature process with diginal PID coutrollern.

\section{Test: fill in the blanks}

1) These sensors provide a voltage output signal which is propertional to the measured.

2) The ......... is used to smooth the output of the fill wave bridge rectifien

The Bridge diode and Power MOSFET Transistor moanted on a w.....in order to protect them from the effects of the overbeat caused by the curreat.

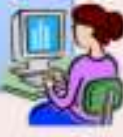

\section{answer}

1) Temperature

2) Capacitor

3) Heat sink

\section{References}

[1] Z.H. Yu, and W. Xu-Yong, "Nonlinear Control for A Class of Hydraulic Servo System," Journal of Zhejiang University http://www.zju.edu.cn/jzus, 2003. Science, 
[2] P. Klingstam, B.G. Olsson, "Application of Simulation for Manufacturing Processes Improvements: using Simulation Techniques for Continuous Process Verification in Industrial System Development," Proceeding of the $32^{\text {nd }}$ Conference on Simulation Orlando, Florida 2000.

[3] S.R. AL-Sakini, "Expert System for Fault Diagnosis in Power Plant Using Artificial Neural Network," Ph.D Thesis to Educational Technology, Electrical Engineering, University of Technology, January 2003.

[4] J.S. Carson, "Introduction to Modeling and Simulation," Proceeding of Simulation Conference, USA, 2003.

[5] Edu Tech Wiki, "Instructional Design Models," 2007.

[6] Neil S/Mc, http:/www.coe .uh.edu/caurses/cuin6373/watisid.2006. Merrill M. David "A Pebble in the Pond Model for Instructional Design," Performance Improvement .vol.41no.7 August 2002.

[7] M.M. David, "First Principle of Instruction," ETR \& D, vol.50, no.3, 2002

[8] Mc Griff Steven J., "Instructional System Design: Using the ADDIE Model," Instructional System, College of Education, Penn state University, 2000.

[9] M. Averil, \& G. Michael, "How to Build and Credible Simulation Models," Proceeding of the Simulation Conference, 2001.

[10] I. Somerville, "Software Engineering," $9^{\text {th }}$ Edition 2011.

[11] J. Mayhew Deborah, "Principle and Guidelines in Soft Ware user Interface Design,” Prentice hall, 2008.

[12] R. Lyman, T. Michael, "Introduction to Statistical Methods," 2016. 